\title{
Exploration and Practice of Integrating Moral Education into College English Reading \&Writing Course
}

\author{
Xuelian Liu \\ School of Foreign Languages, China University of Geosciences, Wuhan, Hubei, P.R. China \\ Corresponding author.Email: liuxl@cug.edu.cn
}

\begin{abstract}
College English course is an important part of the ideological-political system of higher education curriculum. Based on college English reading\&writing course, this paper explores and practices teaching framework of moral education from the aspects of teaching objective, teaching content, teaching mode, teaching evaluation and teachers' development, under the condition of the reduced class hours and the lack of Chinese moral elements in the textbooks.
\end{abstract}

Keywords: moral education, college English reading\&writing course, teaching practice.

\section{INTRODUCTION}

In 2016, Xi Jinping, General Secretary of China, pointed out at the Conference on Ideological-political Work in National Colleges and Universities that "Moral education should be taken as the central link. Ideological-political work should be running through the whole process of teaching." Standing at the strategic height of realizing the great rejuvenation of the Chinese nation, $\mathrm{Xi}$ Jinping has answered the fundamental questions of what kind of talent higher education should cultivate, how to cultivate and for whom, and pointed out the direction for the development of college English education.

In 2020, the Ministry of Education issued the Guidance Outline for Ideological-Political Construction of Curriculum in Colleges. It pointed out that comprehensively promoting ideological-political construction of curriculum is a strategic measure to implement the fundamental task of moral education. Implementing moral education is an important task to improve the quality of college students. The newly issued College English Teaching Guide in 2020 clearly points out that the nature of college English courses is that "College English courses can cultivate students' ability to understand and interpret Chinese culture, and serve the international communication of Chinese culture; core socialist values should be organically integrated into college English teaching. The new teaching objective of college English "is to cultivate the students' English application ability, strengthen the awareness of cross-cultural communication and interpersonal skills; at the same time, to develop students' autonomous learning ability, improve their comprehensive cultural literacy and cultivate humanistic spirit and critical thinking ability, so that they can effectively and appropriately use English in their future study, life, and work to meet the needs of the nation, society, schools and individual development. Also, cultivating students to set up correct world outlook, outlook on life, and values is significant."

Therefore, in this new era, college English teaching should play the role of implementing moral education. College English reading courses provide students with rich reading texts, covering topics such as politics, economy, culture, history, society, science, customs and so on. It provides important input materials for cultivating college students' patriotism, international vision, intercultural communication ability and building up correct values. Therefore, teachers should not only pay attention to the teaching of knowledge and various skills, but also do a good job in shaping students' ideology and values. The ideological-political education is the demand of the new era, and is also an important mission for all college English teachers. 


\section{CURRENT RESEARCH ON IDEOLOGICAL-POLITICAL CONSTRUCTION OF COLLEGE ENGLISH CURRICULUM}

So far, a few Chinese experts have made deep elaboration on the connotation of the curriculum ideology, as well as the significance of implementing it [1][2][3]. Yang Jinhua shared the teaching experience of ideological-political education with a case in a unit [4]. He Yaqin discussed the application of critical thinking in teaching of college English reading in the context of curriculum ideology [5]. Xing Yuqian took New Starting Point College English Comprehensive Course as an example to discuss the ideological- political elements that can be integrated into college English teaching [6].

English reading\&writing course provides students with rich topics like politics, economy, culture, history, science, etc., which are important input materials for them to cultivate patriotism, international vision, cross-cultural communication ability and set up correct values. They are also important for students to output their thought in writing, speaking and translating. In view of the current reform of college English teaching, teaching hours are continuously reduced, learning time in classroom is compressed, and students acquire less and less knowledge in classroom. If following the new teaching objective, besides language and skills, there is no much time in class to fully expand a topic containing Chinese moral element. Moreover, the existing textbooks, such as the comprehensive college English courses published by Foreign Language Teaching and Research Press, Shanghai Foreign Language Education Press and Higher Education Press, cannot fully meet the new teaching requirements and objectives. (Liu Zhengguang, 2020) They lack explicit ideological and political resources and objectives, and the students' learning experience is poor.

Under the current situation of fewer class hours and the lack objectives of moral education in textbooks, the purpose of this study is trying to explore the framework to integrate moral education into college English reading\&writing course, so as to provide reference and ideas for the ideological-political construction of college English courses.

\section{THE IMPLEMENTATION OF IDEOLOGICAL-POLITICAL EDUCATION IN COLLEGE ENGLISH READING\&WRITING COURSE}

Currently, curriculum ideology has become a new educational philosophy. In order to fulfill the fundamental task of moral education, the ideological-political construction of college English reading\&writing course must make new adjustments in teaching objective, teaching content, teaching mode, teaching evaluation and teachers' development, so as to respond to the call of the country and cultivate qualified talents for socialist construction.

\subsection{Resetting Teaching Objective}

Teaching objective should be re-set specifically to each unit. In addition to knowledge and skills that must be mastered in each unit, the objective of moral education should be set according to different topics.

The objectives of moral education are listed in the following dimensions:

(1) Comparison between Chinese and Western cultures: to understand the essence of world culture and the contribution of Chinese culture to human civilization.

(2) Critical thinking ability: to make rational thinking and judgment; to distinguish facts from opinions.

(3) Humanistic education: friendship, environmental protection, appreciation, etc.

(4) Chinese culture communication and expression: to tell Chinese stories in English; to disseminate Chinese culture.

(5) Spirit of the times: core socialist values; a community with a shared future for mankind.

The objective of moral education can be more detailed. For example, when learning the topic of friendship, such excellent qualities as integrity, friendliness, care, support and tolerance can be cultivated. Through the input of text content and the output of topic-based writing, socialist values can be practised at the level of individuals. Take the topic of occupation as another example, moral elements are love, responsibility, and dedication. Students should not only know that they should take responsibility and work hard in their positions, but also know that when national interests and personal interests conflict, they should have the spirit of dedication and put national interests first. The dedication of medical staff, community workers and volunteers to fight against COVID-19 regardless of personal safety is a very good teaching material, which is just the right way to integrate the scientific spirit, responsibility and patriotism into teaching practice.

\subsection{Reconstructing Teaching Content}

Teaching content is based on teaching objectives. After adding the objective of moral education, teaching content must be reconstructed. Teachers should deeply explore the the moral elements of existing resources based on the theme, making full use of the explicit ideological-political resources, and supplementing 
materials related to the moral goal, such as reading materials, audio and video, or pictures as the input material. In class activities, teachers should promote the students' spirit of collaboration and deepen their learning experience through questions, oral report, project-based group discussion or presentation. After class, exercises such as translation and writing will boost the students' language output ability. Reading can promote both the ability of writing and translation, so as to strengthen educational function and drive deep learning.

The teaching objective of moral education should be infiltrated before, in- and after class to have an imperceptible influence on students. For instance, in Text A of Unit 5 New Horizons College English 2 Reading\&Writing Course, the topic of whether to save money or spend is discussed. Core American values is mentioned like working hard, family loyalty and the capacity to postpone desires, which make the United States great according to the author. Based on this explicit moral element, teachers can guide students to compare Chinese and Western cultures and summarize the similarity through group discussion. Actually, Chinese people worship these qualities as well. Hard work and frugality (艰苦奋斗, 勤俭节约) are Chinese excellent qualities. In this way, students can accumulate some vocabulary like thrifty, frugal to talk about Chinese stories or disseminate Chinese culture. After class, students are required to write an essay about 200 words based on the previously supplemented material about the Long March, sharing their feelings and what they can learn after reading it.

\subsection{Restructuring Teaching Mode}

Due to the limited teaching time in classroom, this study adopts the blended teaching mode of online and offline to extend learning space and time, so that students have more time to learn and internalize the teaching content.

Before class, teachers use QQ group or online teaching platform $U$ Campus to assign tasks about a certain moral content. Students are required to read text materials or watch relevant videos in advance to complete online self-study.

In class, 15-20 minutes are reserved for group discussion or oral report on the uploaded content, and students are required to communicate and share with other students so as to make good preparation for text learning. More in-depth teaching activities based on students' previous learning results are carried out, integrating moral education into the teaching process. Question answering and student-centered activities make them think deeply and learn more from practice. Experiential activities like watching video or listening to the lecture will strengthen the teacher-student and student-student interaction.
After class, writing tasks will be assigned related to moral topics through the writing platform iWrite, or relevant translation exercises of sentences or paragraphs will be provided, which will help students enhance their output ability to achieve the purpose of moral education.

\subsection{Reconstructing Evaluation Standard}

After integrating the objective of moral education, whether to improve students' personal quality and form correct values will be the evaluation standard. Both "language" and "thought" will be evaluated. Besides language, the ideological content, values, attitudes contained in language forms are added to evaluate the learning effect of students. The assessment is based on the students' output in- and after class.

In group activities, peer evaluation and self-evaluation enable participants to have a deeper reflection on learning. Teachers should give affirmation and recognition to students' learning attitude and progress, and play a good role as supervisors to guide students to reflect in time. Teachers also need to correct the mistakes of students' thoughts and behaviors, so as to better implement value guidance.

\subsection{Improving Teachers' Personal Competence}

The new edition of College English Guide in 2020 requires English teachers to have five core competences, among which moral competence is one of them. As the implementer of moral education, teachers' awareness as well as understanding and cognition level of it directly affect the teaching effect. Therefore, teachers should be teachers with four "goods", which are ideals and beliefs, moral sentiment, solid knowledge and benevolence. Only in this way, teachers can effectively influence students' thoughts, behaviors and become their guides.

In class, some moral elements are not so explicit, but the language and behavior of a teacher can show his or her attitude and stance, and also form a certain influence on the students. Therefore, teachers should set a good example for students in words and action, always remembering "what kind of talents to cultivate, how to cultivate them and for whom". It is an important responsibility for English teachers to integrate the needs of the country, the goals of the school with their own teaching.

\section{CONCLUSION}

College English, as a required course in higher education, is humanistic in itself, and is an important subject for implementing moral education. English reading\&writing course is text-based, and the theme involves all aspects of humanistic education, which contains the relationship between man and society, man and nature, and man and man, etc., embracing its own 
value orientation and educational function. The deficiency lies in the lack of Chinese ideological and political elements. What teachers need to do is to integrate these elements into the teaching process. While learning the text, teachers should guide students to conduct cross-cultural comparative study, correctly understand and appreciate the excellent Chinese and foreign cultures, tell Chinese stories well, cultivate students' patriotism and international vision. With the texts as its carrier, English reading \&writing course carries value orientation and humanistic function. As the executor of moral education, besides professional knowledge, teachers should improve their own cultural, pedagogical and ideological competence. Through resetting the teaching objective of moral education, adjusting the teaching content according to the objective, reconstructing teaching mode and assessment standard, they can integrate moral elements into the teaching process at different stages to achieve the aim of moral education.

\section{REFERENCES}

[1] Q.F.Wen, A Framework of Integrating Moral Education into College Foreign Language Teaching, Foreign Languages in China, 2021, pp. 47-52.
[2] Z. G.Liu, Resetting the Educational Philosophy and Restructuring Learning Content to Implement Morality Cultivation in Foreign Language Course Instruction, Journal of Foreign languages, 2020, pp. 21-29.

[3] J.Y. Zhang, N. Wang, Construction of Foreign Language Courses with Ideological-Political Elements: Components, Principles and Methods, Foreign Languages in China, 2020, pp. 15-20.

[4] J. H.Yang, Exploration and Practice of Integrating Ideological and Political Elements into College English Curriculum -- Taking "Man and Nature" in Unit 4 of College English Reading and Writing Course as an Example, Industrial \& Science Tribune, 2020, pp. 152-153.

[5] Y.Q. He, The Application of Critical Thinking Teaching Based on Ideology and Politics in College English Reading Course, Journal of Higher Education, 2020, pp. 130-133.

[6] Y.Q. Xing , An Analysis of Ideological and Political Elements in College English Courses -- Taking New Starting Point College English Comprehensive Course as an Example, English Square, 2020, pp. 97-99. 